\title{
La sinodalidad como elaboración conjunta de decisiones: salir del punto muerto del votum tantum consultivum
}

\author{
Alphonse Borras* \\ Universidad Católica de Lovaina (Bélgica) \\ Alphonse.borras@evechedeliege.be \\ Recibido 05.05.2021/ Aprobado 30.05.2021 \\ DOI: $h$ ttps://doi.org/10.46553/teo.58.135.2021.p93-111
}

\section{RESUMEN}

La Iglesia es sinodal, lo cual implica desde una eclesiología participativa la corresponsabilidad de todos los fieles. En esa perspectiva, resulta problemático para una sensibilidad democrática moderna la calificación de «solo consultivo» de los órganos participativos propuestos por el Código de derecho canónico. Tras haber evocado el anclaje de la sinodalidad en el misterio de la Iglesia, el autor recuerda que dicho concepto alude tanto a un estilo, un habitus, como a procesos e instituciones que implican el protagonismo de todos los fieles al igual que el papel singular del ministerio pastoral. De ahí concluye en la inadecuación del binomio de carácter jurídico "consultivo-deliberativo" para hacer resaltar a la vez el peso eclesiológico del dictamen común y la relevancia igualmente eclesiológica de la elaboración conjunta de las decisiones, in ecclesia.

Palabras clave:Eclesiología; Sinodalidad; Participación; Consulta; Deliberación; Voto consultivo; Decisión making / decision taking; Sínodo diocesano; Consejo pastoral; Consejo presbiteral

Synodality as a Joint Elaboration of Decisions:

Breaking the Deadlock of the votum tantum consultivum

- El autor es profesor emérito de la Facultad de Derecho Canónico de la Universidad Católica de Lovaina. 


\section{ABSTRACT}

The Church is synodal, which implies, from a participatory ecclesiology, the co-responsibility of all the faithful. In this perspective, the qualification of the participatory bodies proposed by the Code of Canon Law as "only consultative» is problematic for a modern democratic sensibility. After evoking the anchoring of synodality in the mystery of the Church, the author recalls that this concept alludes both to a style, a habitus, and to processes and institutions that involve the protagonism of all the faithful as well as the singular role of the pastoral ministry. From there he concludes on the inadequacy of the juridical binomial "consultative-deliberative" to highlight both the ecclesiological weight of the common opinion and the equally ecclesiological relevance of the joint elaboration of decisions, in ecclesia.

Key words: Ecclesiology; Synodality; Participation; Consultation; Deliberation; Consultative vote; Decision Making / Decision taking; Diocesan Synod; Pastoral Counsel; Presbyteral Counsel

La Iglesia es sinodal. En otros términos, la sinodalidad es una dimensión constitutiva del pueblo de Dios. En cuanto dimensión esencial, significa que lo es desde sus orígenes, pero mediante una variedad de realizaciones o figuras históricas. Lo es hoy como lo fue en el pasado, así como lo será en el futuro. Dimensión constitutiva, no porque lo haya dicho el papa Francisco ${ }^{1}$ sino porque tanto la naturaleza comunional como la finalidad misionera de la Iglesia son de por sí "sinodales". Lo cual nos invita a valorar la escucha de todos los fieles, su protagonismo eclesial y su participación en los procesos decisionales. Ahora bien, si mantenemos ese rumbo inducido por una eclesiología del pueblo de Dios, topamos con lo que muchos perciben como una visión minimalista de la consulta eclesial ya que, en los órganos de participación, los fieles solo tienen voto consultivo. A nivel del voto deliberativo, cabe constatar en el Código de derecho canónico de 1983 un lamentable minimalismo e incluso un déficit total de implicación de los bautizados, en la vida diocesana y sobre todo parroquial. ${ }^{2}$

1 Papa Francisco, Conmemoración del 50 aniversario de la institución del Sínodo de los obispos, http://www.vatican.va/content/francesco/es/speeches/2015/october/documents/papa-francesco_20151017_50-anniversario-sinodo.html; consultado el 10 de febrero de 2021 .

2 Cf. Ugo Sartorio, "Sinodalità per una Chiesa in riforma», Studia Patavina 66 (2019): $279-292$ 
Tras haber evocado el anclaje de la sinodalidad en el misterio de la Iglesia, recordaré que dicho concepto alude tanto a un estilo, un habitus, como a procesos e instituciones que implican el protagonismo de todos los fieles al igual que el papel singular del ministerio pastoral. De ahí se concluirá en la inadecuación del binomio de carácter jurídico "consultivo-deliberativo" para hacer resaltar a la vez el peso eclesiológico del dictamen común y la relevancia igualmente eclesiológica de la elaboración conjunta de las decisiones, in ecclesia. $^{3}$

\section{El anclaje de la sinodalidad en el «misterio» de la Iglesia}

La Iglesia en cuanto "misterio", es decir desvelamiento, manifiesta en la historia la convocatoria (gr. ekklesia) por parte de Dios de la humanidad -de todos los seres humanos- a su alianza (cf. Jn 11,52; LG 2, 13a, 48c; AG 2b in fine, 7c; GS 39 § 3). Dios quiere en efecto «que todos se salven y lleguen a la verdad» $(1 \operatorname{Tm} 2,4)$. En otros términos, quiere que los seres humanos sean participes de su comunión de vida divina (cf. 1 Jn 1,3).

En cuanto convocatoria a la alianza, la Iglesia llama hacia fuera (gr. ek-kaleô): ¡es tarea suya! siendo en sí misma extravertida. Su acción tiene lugar fuera de sí mismo, como sugiere la etimología griega. Y esta convocatoria, así como la reunión que resulta de ella, se produjo de manera decisiva gracias a la encarnación del Verbo y a la resurrección de Cristo por el Espíritu de santidad. Mediante este acontecimiento de salvación -en estos tiempos que son los últimos (cf. Hb 1,2)- la humanidad se orienta irreversiblemente hacia aquello para lo que fue creada: escatológicamente hablando, la plenitud de vida, la comunión de gracia, la paz y la reconciliación.

3 Me permito señalar a este propósito dos de mis estudios en este campo: Alphonse Borras, «Délibérer en Église: communion ecclésiale et fidélité évangélique», Nouvelle Revue Théologique 132 (2010): 177-196 ; "Votum tantum consultivum. Les limites ecclésiologiques d'une formule canonique», Didaskalia 45 (2015/1): 145-162. 
La Iglesia no tiene pues su fin en sí misma como, además, tampoco tiene su origen en sí misma. En cuanto pueblo de Dios, nace de la comunión de vida trinitaria, ecclesia ex trinitate. Se desprende del plan o diseño de Dios, de su "misterio", de su deseo de comunicarse a sí mismo y de hacer una alianza. Y por la libre adhesión de los fieles a la iniciativa divina de gracia, tiende o camina hacia la comunión divina, ecclesia in trinitatem. En la espera del día que este plenamente en su comunión de vida, ecclesia in trinitate. Desde esa perspectiva la Iglesia se entiende como el pueblo de Dios que camina en la historia anunciado el Reino de Dios, su plenitud de vida o la gracia de la salvación según que se hable respectivamente como los sinópticos, la literatura juanea o los escritos paulinos.

\section{La sinodalidad, un habitus y sus formalizaciones institucionales}

En cuanto los fieles responden y corresponden libremente por su fe a la iniciativa de gracia, forman parte de la comunión eclesial. La misma palabra "comunión" significa "participación" (cf. lat. cummunus), es decir el hecho de formar parte o ser participes; connota un partnership, una corresponsabilidad. ${ }^{4}$ Por la gracia del bautismo y según sus carismas propios, todos los fieles están orgánicamente unidos en el cuerpo eclesial de Cristo animado por su Espíritu (cf. Rm 12 y 1 Co 12; 1 P 2,5). En la comunión eclesial existe pues una corresponsabilidad constitutiva de todos los bautizados la cual traduce la sinodalidad eclesial, es decir de la ecclesia o comunidad eclesial cualquiera sea su figura concreta. ${ }^{5}$ Por una parte, la noción

4 Es en la exhortación apostólica postsinodal Christifideles laici de 1989 donde, por primera vez en un texto del magisterio pontificio, se dice que los fieles laicos son "corresponsables" de la misión de la Iglesia con todos los ministros ordenados y los religiosos y religiosas (ChL $15 \mathrm{a}$, cf. $21 \mathrm{a}$ in fine). Cf. Alphonse Borras, "La coresponsabilité : enjeux théologiques et institutionnels», en Olivier Bobineau \& Jean Guyon, La coresponsabilité dans l'Église, utopie ou réalisme (Paris: Desclée de Brouwer, col. Religion \& Politique, 2010), 69-89.

5 El término ecclesia puede designar diferentes figuras institucionales de la comunidad de los discípulos de Cristo: La Iglesia particular, en este caso la diócesis como Iglesia realizada en un lugar, una agrupación de Iglesias particulares, como una provincia Eclesiástica o una Conferencia Episcopal, así como la comunión de todas estas Iglesias locales en cuanto Iglesia universal, sin olvidar, por supuesto, las demás comunidades eclesiales que los fieles constituyen bien en virtud de una erección por parte de la autoridad competente -parroquias, capellanías hospita- 
de corresponsabilidad expresa así una cualidad y un cargo de los fieles y, por otra, desde el punto de vista eclesial, el concepto de sinodalidad designa una propiedad y una función de la comunidad. La sinodalidad eclesial es plural, como lo es la corresponsabilidad diferenciada de los bautizados por la variedad y complementariedad de sus carismas.

La comunidad eclesial es pues esencialmente sinodal no solo en el sentido de caminar, juntos y cada uno según su ritmo, sino también en el sentido de cruzar el mismo umbral, de permanecer juntos, y por tanto de reunirse. ${ }^{6}$ El concepto de sinodalidad, de por sí abstracto, se puede declinar en el tríptico estilo - estructuras/ procesos - acontecimientos, tal como lo afirmaba en 2018 la Comisión teologica internacional (CTI). ${ }^{7}$ Los acontecimientos sinodales presuponen un habitus, un estilo, y su formalización institucional; no son nada más que la implementación concreta de las instituciones sinodales a nivel local, regional y universal, involucrando al pueblo de Dios y sus pastores $\left(\mathrm{n}^{\circ} 70 \mathrm{c}\right)$.

En efecto, «la sinodalidad designa ante todo el estilo peculiar que califica la vida y la misión de la Iglesia expresando su naturaleza como un caminar juntos y un reunirse en asamblea del pueblo de Dios convocado por el Señor Jesús en la fuerza del Espíritu Santo para anunciar el Evangelio». ${ }^{8}$ Por tratarse "ante todo" de un "esti$10^{\prime \prime}$ se subraya así el aspecto informal o habitual en cuanto presupuesto de la vida eclesial que luego se expresa "en el modo ordinario de vivir y obrar de la Iglesia" ( $\mathrm{n}^{\circ} 70 \mathrm{a}$ ). Siendo la sinodalidad constitutiva de la vida eclesial, siempre ha determinado más o menos - en

larias, penitenciarias o estudiantiles, etc. - o por ser institutos de vida consagrada o sociedades de visa apostólica o bien en virtud de su libertad de asociación, asociaciones privadas o públicas.

6 La etimología corriente proviene del griego synodia, que se refiere a un grupo de personas que caminan juntas (sun [con] y hodos [camino]). Stal vez haya también que tener en cuenta la siguiente etimología: el prefijo sun- [con] y la palabra oudos en griego clásico [umbral] que proviene del dialecto ático (jcon espíritu amable!) y que significa "el umbral de la casa" y no hodos (icon espíritu áspero!) que significa "camino". Cf. Arnaud Join-Lambert, Les liturgies des synodes diocésains français 1983-1999 (Paris: Éd. du Cerf, col. Liturgie n¹ 5, 2004), 61-65.

7 https://www.vatican.va/roman_curia/congregations/cfaith/cti_documents/rc cti_20180302_sinodalita_sp.html; consultado el 24 de febrero de 2021.

$8 \mathrm{CTI}$, La sinodalidad en la vida y la misión de la lglesia, n $70 \mathrm{a}$. 
grados muy diferentes según la época y el lugar - el estilo de la convivencia entre los fieles y del ejercicio de la autoridad pastoral, tratándose como mínimo en «no caminar solos» (cf. EG 33 in fine). Si durante estos últimos siglos el estilo sinodal ha parecido ser más bien minimalista en la Iglesia católica latina, hoy día gracias a la impulsión del papa Francisco podría volver a ser un habitus que dinamiza la vida eclesial y el ministerio pastoral.

Pero la sinodalidad eclesial que se realiza en el ejercicio de la corresponsabilidad de los fieles se traduce institucionalmente «en sus diferentes niveles y en la distinción de los diversos ministerios y roles, en su vida y en su misión» $\left(n^{\circ} 70 \mathrm{~b}\right)$. El estilo sinodal tiene pues que verificarse formalmente - y no solo habitualmente - en mayor o menor medida en lo cotidiano de una comunidad cristiana en sus «estructuras»y sus «procesos» (Ibid.), ${ }^{9}$ los cuales están al servicio del discernimiento eclesial con miras a su misión evangelizadora ya que «la salida misionera es el paradigma de toda obra de la Iglesia» (EG 15; citando a Juan Pablo II, RM 34, 40 y 86). El discernimiento requiere conjuntamente «escucha de Dios, hasta escuchar con él el clamor del pueblo; (y) escucha del pueblo, hasta respirar en él la voluntad a la que Dios nos llama». ${ }^{10}$ Mediante ese discernimiento comunitario para conocer lo que el Espíritu «dice a las Iglesias» (Ap $2,7)$ toca a la autoridad eclesial indicar a la comunidad la dirección que debe seguir (CTI n $\left.{ }^{\circ} 70 b\right)$.

Concretamente, considerando el pueblo de Dios a partir de las Iglesias particulares -desde las cuales y hacia la cuales se despliega la dinámica sinodal- ${ }^{11}$ el obispo asume su rol de autoridad

9 Aquí la CTI usa de un lenguaje más bien sociológico, que el jurista y con mayor razón el canonista traducen por «instituciones» $y$ «procedimientos» $\left(\mathrm{n}^{\circ} 70 \mathrm{~b}\right)$.

10 Papa Francisco, Conmemoración del 50 aniversario, discurso del 17 de octubre 2015 , véase la $\mathrm{n} .1$.

11 Aquí aludo a la Constitución apostólica Episcopalis communio que, más allá de la mera celebración de un Sínodo de obispos, induce una dinámica sinodal "generalizada" que, mediante la consulta de los fieles, parte del pueblo de Dios en las Iglesias particulares con miras al discernimiento de la asamblea sinodal y al pronunciamiento del papa, para luego volver en ellas, lugar de implementación del proceso sinodal y de recepción de sus conclusiones. Cf. Alphonse Borras, "Episcopalis communio, mérites et limites d'une réforme institutionnelle», Nouvelle Revue Théologique 141 (2019/1): 66-88. 
eclesial y fomenta la comunión misionera según una triple postura: estando a veces delante para indicar el camino, otras veces en medio de su pueblo con su cercanía misericordiosa y en ciertas ocasiones detrás de él (cf. EG 31). Esta tercera postura merece ser subrayada no solo ni tanto «para ayudar a los rezagados», sino «porque el rebaño mismo tiene su olfato para encontrar nuevos caminos» (Ibid.).

\section{El protagonismo de todos los fieles y su corresponsabilidad eclesial}

Esa triple postura de los obispos, en cuanto pastores del pueblo de Dio, ¡vale para todos los demás pastores! De ahí la insistencia sobre su deber de «alentar y procurar la maduración de los mecanismos de participación que propone el Código de Derecho Canónico ${ }^{12}$ y otras formas de diálogo pastoral» (Ibid.). ${ }^{13}$ Esos órganos de participación y las demás formas de diálogo consisten esencialmente en «escuchar a todos» y tienen como fin principal no la «organización eclesial, sino el sueño misionero de llegar a todos» $\left(\right.$ Ibid.). ${ }^{14}$

Nótese sin embargo que lo que "propone" el Código de 1983 se refiere a órganos consultivos cuyo voto es solo consultivo (lat. votum tantum consultivum) tal como lo califica el mismo legislador o que la lengua castellana expresa afortunadamente por órgano "con voz" cuyo antónimo es el de órgano deliberante "con voz y voto". Esa normativa del "solo consultivo" va en contra de la sensibilidad

12 En la nota 34 de EG 31 , el papa Francisco se refiere expresamente al Sínodo diocesano (cc. 460-468), al Consejo presbiteral (cc. 495-502, y no "492-502" como se lee en todas las versiones del sito del Vaticano), al Consejo pastoral diocesano (cc. 511-514) y al Consejo pastoral parroquial (c. 536). Esa lista no tiene que entenderse como limitativa ya que el mismo papa habla de las otras formas de diálogo.

13 Vale la pena comparar varias versiones de la $E G 31$ en sus respectivas lenguas: el casteIlano habla de «mecanismos» como la versión inglesa habla de «medios», means; en cambio las versiones francesa, italiana y portuguesa hablan de «organismos» así como la versión alemana utiliza la palabra de regulación o normativa, o sea «dispositivos de participación», Mitspracheregelungen.

14 Me gusta citar a Pablo VI a propósito del Consejo pastoral diocesano, cuya finalidad es promover "la conformidad de la vida y la acción del Pueblo de Dios con el Evangelio». Esto se aplica a fortiori a todos los Consejos en la Iglesia cuyo sentido consiste en verificar el "tono evangélico" de la comunidad eclesial. Véase el Motu proprio Ecclesiae sanctae del 6 de agosto de 1966, núm. $16 \S 1$ in fine: ita ut in vitae et actionis Populi Dei conformitas cum Evangelio promoveatur. Lamentablemente, esta aclaración no se incluyó en el Código de 1983. 
democrática actual. ¡Las aspiraciones legitimas de participación de muchos fieles se ven defraudadas! De ahí una discrepancia entre las exigencias de la modernidad y las prácticas eclesiales en cuanto a la participación de los fieles en su seno con miras a su papel evangelizador y las decisiones que se requieren a ese efecto.

No cabe duda de que de facto hay un déficit de participación en las decisiones relativas a la vida de la Iglesia y a su misión. El mismo papa Francisco observó -cuando no deploró a media voz- que, en parte, la responsabilidad eclesial de los laicos «no ha encontrado espacio en sus Iglesias particulares para expresarse y actuar, a causa de un excesivo clericalismo que los mantiene al margen de las decisiones» (EG 102). Pero no es ¡solo cuestión de clericalismo individual!, sino de funcionamiento institucional que contradice el protagonismo teóricamente profesado de todos los fieles sobre los cuales reposa la misión evangelizadora del pueblo de Dios.

Ahora bien, la perspectiva es inclusiva: ¡todos los fieles! Son todos activos y corresponsables según sus vocaciones, carismas y eventualmente ministerios propios (cf. ChL 21a in fine) ya que, en base de su función profética y del sensus fidei (omnium) fidelium, forman parte de la comunión orgánica del pueblo de Dios y se han vuelto participes de su misión. De ahí que, volviendo a las palabras del papa, todos los fieles contribuyen a la «comunión dinámica, abierta y misionera» de la cual cuidan los pastores (EG 31). Correlativamente toca a estos de escuchar «a todos» (Ibid.). Para ello, no bastan unas buenas intenciones sino hechos, actos, actuaciones. Cierto cada fiel asume por parte suya su vocación dentro de la misión de la Iglesia, concretamente en su vida cotidiana. Aquí se trata sin embargo de los fieles en cuanto ecclesia, comunidad de discípulos-misioneros, como sujeto eclesial "en este lugar", es decir en su entorno humano, concreto y habitual. Para ello se necesitan lugares institucionales, órganos participativos que sean espacios de escucha, reflexión, debate, propuesta e impulsión entre los fieles con sus pastores. 


\section{La singularidad simbólica del cuerpo eclesial}

Sin embargo, el estatus del ministerio apostólico induce una relación asimétrica con los demás fieles. Hay por lo menos una asimetría entre los bautizados y los ordenados que es constitutiva y estructurante de la ecclesia (cf. c. $207 \S 1$ ). ${ }^{15}$ Así pues, todos los fieles atestiguan por su condición bautismal que no hay Iglesia sin adhesión de fe, y a la vez los ministros ordenados atestiguan que no hay Iglesia sin la gracia de Dios. La Iglesia en efecto no resulta de un contrato social o de la voluntad asociativa de los fieles, sino de su respuesta libre a la iniciativa graciosa de Dios, por Cristo en su Espíritu. Los fieles, ministros incluidos, significan y realizan conjuntamente que no hay cuerpo eclesial sin compromiso de fe anunciándola, celebrándola y atestiguándola en ese mismo triple plano profético, sacerdotal y real (cf. c. 204 § 1). Todos los fieles constituyen propiamente la congregatio fidelium, la comunidad de discípulos-misioneros dentro y al servicio de la cual el ministerio ordenado significa y atestigua que (pro)viene de Dios por medio de Cristo en el Espíritu (cf. c. $207 \S 1$ ).

El ministerio ordenado -la apostolicidad del ministerio- ${ }^{16}$ estructura la ecclesia en el sentido que mantiene esa polaridad entre iniciativa de la gracia y respuesta de la fe $y$, por tanto, desde esta misma, mantiene la relación "simbólica" e incluso "sacramental" entre todos los fieles y los pastores. Estos últimos significan y realizan la única mediación sacerdotal de Cristo, que no puede separarse en modo alguno de sus funciones proféticas y reales. Único verdadero sacerdote, profeta escatológico y buen pastor, Cristo encabeza su cuerpo eclesial que el Espíritu de santidad no deja de animar. Los pastores lo manifiestan sacramentalmente en su ministerio

15 Esa asimetría es propiamente "simbólica", del verbo griego sun-ballein, mantener juntos, lo contrario de "diabólico" que proviene de dia-ballein, dividir, separar.

$16 \mathrm{El}$ sacramento del orden -de modo eminente en el ministerio episcopal- ancla de por sí a la comunidad en la apostolicidad de la fe heredada de los apóstoles y vivida en el Espíritu, en una comunión a la vez diacrónica (a lo largo de los siglos atestiguando la apostolicidad con los orígenes) y sincrónica (entre Iglesias locales atestiguando su apostolicidad mediante la colegialidad episcopal). 
de presidencia de la Iglesia y de su eucaristía, asistidos por cierto por los diáconos. Mediante su ministerio la Iglesia esta llamada a convertirse en un pueblo sacerdotal, profético y real en su totalidad, lo cual atañe a todos los fieles, ministros incluidos que no dejan de ser fieles "bautizados". La asimetría manifiesta sin embargo una desigualdad entre los fieles que se repercute en los procesos de toma de decisiones. La participación de los fieles no puede por tanto ser "deliberativa" en el sentido propiamente jurídico que presupone en base de un número igual de votos, que tomen decisiones por mayoría simple o cualificada. Los órganos que "propone" el Código en términos de participación son meramente consultivos. Su normativa parece pues contradecir el protagonismo eclesial teóricamente profesado.

\section{La inadecuación del binomio consultivo-deliberativo}

Desde la común dignidad bautismal, propiamente fundamental y básica, se mide la inadecuación del binomio consultivo-deliberativo a la hora de considerar y poner en práctica la participación de todos los fieles en las decisiones relativas a la vida de la Iglesia y su misión. Hace ya más de treinta años, el Profesor Francesco Coccopalmerio -hoy día cardenal de la Iglesia romana- fue muy claro en lo que pensaba cuando, tratándose del Consejo pastoral parroquial, afirmaba que la expresión votum tantum consultioum resultaba inadecuada si se entendía en el sentido del derecho civil. ${ }^{17}$ Es incluso lamentable si se prescinde de una visión orgánica de la comunión, de la corresponsabilidad diversa de todos, de la originalidad del ministerio apostólico y, en definitiva, de la sinodalidad fundamental de la comunidad eclesial.

17 Francesco Coccopalmerio, De paroecia (Roma: Ed. Pontificia università gregoriana 1991), 172-174. Véase también su estudio: "La "consultività" del Consiglio pastorale parrocchiale e del Consiglio per gli affari economici della parrocchia", Quaderni di Diritto ecclesiale 1 (1988): 60-65. 
En efecto, ceñirse "solo" al proceso consultivo descalifica la igualdad radical y fundamental de todos los fieles que no se sienten, e incluso no son tomados en serio como hermanos y hermanas en la fraternidad eclesial. Al opuesto, si ceñimos el solo aspecto deliberativo, borramos la función estructurante del ministerio apostólico. Ahora bien ¿cómo pues entender el binomio? Si lo entendemos en un modo binario, la participación consultiva de los fieles es tal porque no puede ser deliberativa. De lo que se desprende de la legislación canónica vigente, la actividad deliberativa se despliega en efecto en asambleas formadas principalmente, si no exclusivamente, por obispos al nivel de agrupaciones de Iglesias particulares, sínodo de obispos y concilios particulares y ecuménicos. ${ }^{18}$ Correlativamente, en esta visión binaria, las demás asambleas diocesanas o inter-diocesanas son consultivas por su composición necesariamente "mixta", es decir con obispos y no obispos, es decir con los demás fieles, a riesgo de hacer que estos últimos acaben jugando -en el peor de los casos- el papel de títeres de los primeros. ¿Significa la falta de voto deliberativo que los fieles solo tienen voto meramente consultivo? Una tal visión binaria del binomio magnifica indebidamente el papel de la jerarquía -como si estuviera por encima del pueblo de Dios- $y$, por tanto, no honra realmente la dignidad común de los fieles. Deja muchos fieles perplejos y les causa bastante frustración por no ser tomados en serio. Tal vez este binomio ¿haya que entenderse en su polaridad?

Para salir del atolladero de una visión binaria del binomio, me remito a una circular de la Congregación del Clero del 11 de abril de

18 La falta de protagonismo de los fieles laicos es aún más flagrante en lo que respecta a una agrupación de Iglesias particulares. Los obispos tienen sufragio deliberativo en los concilios particulares y en las Conferencias episcopales, pero las decisiones que aprueban deben basarse en una mayoría cualificada y están sujetas a modalidades de recognitio por parte de la Sede Apostólica (cc. 445 y $455 \S 2$ ). Y finalmente, en el plan de la Iglesia universal, los obispos en un concilio ecuménico tienen voz en las deliberaciones, pero los decretos conciliares deben ser aprobados por el papa en unión de los padres conciliares, confirmados y aprobados por él (cf. c. 341 \$1); fuera de un concilio los decretos del colegio de obispos necesitan su confirmación y promulgación pontificia (cf. c. 341 §). El Sínodo de los obispos tiene poder deliberativo solo por concesión del papa (cf. c. 343). 
1970, Presbyteri sacra ordinatione. ${ }^{19}$ Ofrecía una descripción del carácter consultivo del Consejo Presbiteral que merece ser citada porque también se aplica a los demás casos, sínodo diocesano y consejos pastorales mencionados anteriormente. Decía: «[El Consejo Presbiteral] se dice que es consultivo porque no tiene voto deliberativo». Y la Congregación añadía: «Por lo tanto, no puede tomar decisiones que sean vinculantes para el obispo, a menos que la ley de la Iglesia universal o el obispo, en casos específicos, le den el voto deliberativo». Obviamente lo que hay que salvaguardar es la libertad pastoral del obispo en virtud de su ministerio apostólico.

El mismo documento romano de 1970 calificaba al Consejo Presbiteral como un «órgano consultivo de carácter peculiar», haciendo luego dos aclaraciones. Por un lado, las deliberaciones se llevan a cabo en unión con el obispo y nunca sin él, a través del trabajo común (cf. $n^{\circ}$ 9c). En cambio, la decisión corresponde al obispo, que es el responsable personal ( $c f . n^{\circ} 9 \mathrm{~d}$ ). En otros términos, la deliberación en la Iglesia se realiza con la ayuda de todos, nunca sin la autoridad pastoral que toma la decisión personalmente.

\section{El principio de no apartarse del dictamen concorde (cf. c. $127 \S 2,2^{\circ}$ )}

Demos un paso más para ver el "carácter peculiar" de la consulta. Volviendo al Código de derecho canónico, descubrimos que consultar es más que escuchar. Quien consulta o toma el consejo de un individuo o de una comunidad, se compromete mucho más, e incluso se obliga a sí mismo en cuanto ya no puede comportarse como si no les hubiera pedido su opinión. El Código prevé las condiciones de validez de la consulta individual y colectiva. Cuando un superior necesita el consejo de un grupo de personas o de un

19 https://www.vatican.va/roman_curia/congregations/cclergy/documents/rc_con_cclergy_doc_19700411_presbyteri-sacra_it.html; consultado el 20 de febrero de 2021 . 
colegio, debe convocarlo y consultarlo según el derecho (c. 127 § 1 y c. 166; cf. cc. 166-173 y los estatutos del órgano en cuestión). ${ }^{20}$

Tanto en una consulta colectiva (c. $127 \S 1$ ) como en una individual (\$ 2), el Código dispone lo siguiente: «Aunque el superior no tenga ninguna obligación de seguir ese parecer, aun unánime, no debe sin embargo apartarse del dictamen, sobre todo si es concorde, sin una razón que, a su juicio, sea más poderosa» (c. $127 \S 2,2^{\circ}$; cf. CIC 1917 c. 105). De esta disposición se desprenden dos lecciones de mayor importancia. Por un lado, el superior que consulta sigue siendo libre; por otro, no se apartará del dictamen sin una razón imperiosa (lat. sine praevalenti ratione). Por regla general, en la práctica, el superior seguirá las opiniones coincidentes de las personas a las que ha consultado. No está jurídicamente obligado a hacerlo, pero generalmente lo hará. Si se empeña en no seguir las opiniones concordes, su credibilidad acabará viéndose seriamente dañada porque tomará su decisión de modo aislado del grupo o individuos de los que es responsable y que están de alguna manera relacionados con él, y él con ellos.

Debido a la ignorancia de muchos en materia canónica y más aún a los prejuicios contra el derecho eclesial, es de lamentar que no se conozcan ni por tanto se practiquen los principios básicos de la consulta enunciados en el canon 127. Convendría sin embargo que se enuncien de forma más adecuada teniendo en cuenta no el aspecto colegial en sentido estricto, sino el aspecto corporativo de los Consejos en la Iglesia que implican su carácter orgánico e incluyen la relación simbólica entre los miembros y su superior. He aquí el propósito de este estudio.

20 En este caso, para que el acto de consulta sea válido, el superior debe solicitar la opinión de todos (c. $127 \S 1$ ). En otras palabras, no puede proceder de forma ecléctica o selectiva; es el grupo o el colegio como tal el que debe solicitar. Cuando, para realizar un acto, el superior debe recabar la opinión de los particulares, el acto es inválido si no los oye (c. $127 \S 2$ ). 


\section{Elaborar juntos las decisiones que le toca tomar a la autoridad pastoral}

En ese sentido, la Instrucción In Constitutione apostolica de 1997 sobre los sínodos diocesanos recuerda que los miembros del sínodo no le son "ajenos", ya que forman parte de él y colaboran activamente en la elaboración de las declaraciones y decretos ( $\left.{ }^{\circ} \mathrm{I}, 2 \mathrm{a}\right){ }^{21}$ ¡Acordémonos aquí del verbo "elaborar"! La Instrucción continúa diciendo -notemos que ya lo dijo Presbiteri sacra ordinatione- que «el obispo sigue siendo libre de seguir el resultado de las votaciones, incluso si sigue la opinión comúnmente compartida por los miembros del sínodo, a menos que haya una razón seria para hacerlo, que le corresponde evaluar coram Domino» ( $\left.\mathrm{n}^{\circ} \mathrm{IV}, 5 \mathrm{~b}\right)$.

En forma similar, el Directorio Apostolorum Successores de 2004 sobre el oficio pastoral de los obispos ${ }^{22}$ subraya el carácter orgánico de la comunión eclesial y de los órganos de participación (n. 165) y, en el sentido del canon $127 \S 2,2^{\circ}$, prescribe que el obispo no debe apartarse de las opiniones o votos expresados por una amplia mayoría «a no ser que haya razones graves de carácter doctrinal, disciplinario o litúrgico» (n. 171a). Así pues, en un órgano consultivo, los fieles a los que los pastores piden su opinión elaboran junto con ellos las decisiones relativas a la vida, el gobierno, el testimonio y la misión de la comunidad. En otros términos, los pastores no rigen ni acompañan el pueblo de Dios sin los fieles que les toca consultar en conformidad con el Código o, en la eventualidad de «otras formas

21 La Instrucción recuerda que un sínodo diocesano no es un colegio con capacidad decisional, es decir con voto deliberativo, y que sus votaciones no entienden alcanzar un acuerdo mayoritario vinculante, sino comprobar el grado de acuerdo de los miembros del sínodo sobre las propuestas realizadas. Como Presbiteri sacra ordinatione en 1970, la Instrucción explica además el carácter "consultivo" por la libertad del obispo diocesano de aceptar o no las opiniones expresadas. En el sitio del Vaticano solo está el texto francés de la Instrucción. https://www.vatican.va/roman_curia/congregations/cbishops/documents/rc_con_cbishops_doc_20041118_diocesan-synods-1997_fr.html; consultado el 20 de febrero de 2021.

22 http://www.vatican.va/roman_curia/congregations/cbishops/documents/rc_con_cbishops_doc_20040222_apostolorum-successores_sp.html; consultado el 23 de febrero de 2021. El mismo n. 171 a añade a este propósito: «El Obispo clarifique rápidamente, si fuera necesario, que nunca se puede contraponer el Sínodo al Obispo en virtud de una pretendida representación del Pueblo de Dios». Lo cual se entiende perfectamente en una perspectiva simbólica de la relación entre fieles y pastores. 
(institucionales) de diálogo», según lo que imponga, a su juicio, el gobierno pastoral de su grey.

A este respecto, las ciencias sociales nos ofrecen una distinción muy útil para honrar la dimensión pneumatológica de la corresponsabilidad bautismal de todos, cada uno según sus carismas, sin perjuicio del ministerio presidencial de los pastores. En la decisión como proceso se hace así mismo hincapié sobre la elaboración: se trata de la distinción de los anglosajones entre la elaboración de decisiones (decision-making) y la toma de decisiones (decision-taking).

Todos los fieles son participes de la elaboración de la decisión la cual presupone el examen de la situación, la escucha de las personas involucradas así como de la Palabra de Dios para acoger lo que el Espíritu dice a la Iglesia en este lugar, la atención particular a las personas que viven esta situación o la sufren, el compromiso de cada uno por el bien de todos y el interés general, la libertad espiritual de cada uno con respecto a sus propias posiciones, teniendo en cuenta el magisterio de la Iglesia, la voluntad de proceder de forma inclusiva sin prejuzgar las opiniones divergentes, la serenidad para afrontar respetuosamente los conflictos $\mathrm{u}$ oposiciones, el deseo de crear la máxima convergencia en las resoluciones que se propongan, la paciencia para darse el tiempo de discernir, etc. en fin, todos estos elementos que nos permiten calificar de sinodal como la comunión in actu. Vivir este discernimiento en la Iglesia es un proceso de aprendizaje propiamente eclesiogenético. ${ }^{23}$

Así pues el discernimiento no solo se desenvuelve en la Iglesia, sino que hace Iglesia en la medida en que juntos, en su diversidad de vocaciones, carismas y ministerios, los bautizados escuchan la Palabra de Dios en el espejo de la realidad teniendo en cuenta los signos de los tiempos en vista de comprometerse en la historia bajo

23 Cf. Michel Rondet, "Le discernement dans la vie de l'Église», Christus 179 (1998): 275 283 , en particular 280-283, sobre los discernimientos que la comunidad como tal, en su vida institucional, debe efectuar. El autor distingue el discernimiento de los signos de los tiempos, la escucha de la fe de los fieles, la atención a los profetas y la aceptación de las legitimidades $y$ diversidades en el reconocimiento del mismo Espíritu en el corazón de nuestras diferencias. 
la acción del Espíritu Santo, concretamente en su entorno para que venga el Reino de Dios, se acoja su plenitud de vida o la gracia de la salvación.

Este proceso de elaboración colectiva es un proceso que se desarrolla a lo largo del tiempo, conlleva pues su propia temporalidad y cuenta con varios factores, tanto objetivos como subjetivos: la toma de decisión final es, en efecto, el objetivo del proceso, en el que no se trata en primer lugar de alcanzar un acuerdo mayoritario, sino de verificar el grado de acuerdo entre los interesados. Esto será una garantía de que la decisión será recibida, madurada por un discernimiento de la voluntad de Dios con la ayuda de todos los interesados. ${ }^{24}$

\section{Semper in ecclesia, numquam alii sine aliis}

Elaborar una decisión resulta pues ser un verdadero proceso eclesial que requiere el compromiso y ayuda de todos los fieles interesados y de sus pastores que, a su vez, descubren y experimentan que no tienen que decidir a solas ni de forma aislada, sino "en su pueblo", in consilio, es decir de forma sinodal o mejor dicho in sinodo, lo cual equivale a decir in ecclesia. ${ }^{25}$ En esa perspectiva hallamos así el hilo rojo de la gran tradición de los primeros siglos atestigua-

24 A falta de estar estipulado en el Código, el derecho particular de una Iglesia local debe prever que, en sus Consejos Pastorales, escuchando a todos, la comunidad interesada y su pastor elaboren la decisión que le corresponde tomar al pastor. Estipularlo en la ley particular sería un primer baluarte contra los excesos individualistas y autoritarios. Una asamblea "mixta" como la Conferencia eclesial de la Amazonía podría traducir en su funcionamiento esa articulación entre los obispos con voz y voto y los demás miembros con voz sola mediante el tratamiento conjunto, coniunctim, de los asuntos que necesitan desembocar en una toma de decisión: todo el proceso de elaboración incluye a todos a paridad de voz y en base de un dictamen concorde los obispos toman la decisión adecuada por tener "voz y voto" asumiendo así mismo su responsabilidad de ponerla, es decir de insertarla en la comunión eclesial. Cf. Alphonse Borras, "La Conférence ecclésiale pour l'Amazonie, une institution synodale inédite», Ephernerides Theologicae Lovanienses 97/2 (2021): 223-292.

25 Tanto más cuanto que Iglesia y sínodo son sinónimos como lo comentó Juan Crisóstomo (gr. ekklêsía synódou estin ónóma, Exp. In Psalm, 149, 1; cf. PG 55, col. 493) Véase el estudio de Salvador Pié i Ninot, La sinodalitat eclesial. Ekklèsía suvódou estin honoma (St Joan Crisóstom). Lliçó inaugural del curs acadèmic 1993-1994, (Barcelona: Ed. Facultat de Teologia de Catalunya, 1993); así como su tratado, Eclesiología. La sacramentalidad de la comunidad cristiana (Salamanca: Ed. Sígueme, col. Lux Mundi n 86, 2007), 565-566. 
da por los Padres de la Iglesia según la cual los pastores no decidían $\sin$ su consejo, sacerdotes o fieles en la diversidad de figuras que podían existir de la sinodalidad.

Así mismo se sale del minimalismo del "solo consultivo" tomando en serio el dictamen concorde por el cual actúa el Espíritu de santidad que anima toda la Iglesia. Eclesiológicamente, los órganos de participación no pueden ser rebajados a ser "solo consultivos" ya que el Espíritu ha sido dado al cuerpo eclesial de Cristo, no solo en este lugar sino en comunión con todas las Iglesias. Participan de una dinámica eclesiogenética.

Todos y cada uno según su vocación, carismas y ministerio participan en el discernimiento comunitario mediante el cual se va elaborando lo que importa decidir, lo cual se consigue in ecclesia con el concurso de todos los fieles, pastores incluidos. Pero al final uno toma la decisión no por ser el "jefe" sino porque, en virtud de su papel en cuanto pastor, hace de "bisagra" entre la comunión en/de su comunidad y la comunión con las demás comunidades eclesiales; en ese sentido "tomar la decisión" es un modo de mantenerla en la comunión eclesial -al mismo tiempo que los fieles mismos, pastores incluidos, se mantienen en la comunión- eso es en una relación de "participación condividida" (shared participation) en la misión común de desvelar (misterio como revelación / desvelamiento) la gracia de Dios que convoca a la humanidad a su alianza. Lo cual, por supuesto, solo puede ocurrir en la historia, de ahí el papel de los signos de los tiempos, etc. y su imprescindible discernimiento porque lo que importa, al fin y al cabo, es que i"venga su Reino"!

Por parte de los pastores - dentro, en medio y detrás del pueblo de Dios - la toma de decisión no es un apoderamiento, una toma de poder sino un servicio para con su propia comunidad y las demás comunidades, y viceversa. Se verifica de ese modo que los pastores están al servicio de la apostolicidad de todo el pueblo de Dios, en el que los fieles colaboran, cada uno a su manera, en la obra común (cf. LG 30, lat. ut cuncti suo modo ad commune opus unanimiter cooperentur). Así como la comunidad no existe y no actúa sin su 
pastor, el pastor no existe ni desenvuelve su papel sin la comunidad. El vínculo simbólico se expresa aquí con más fuerza mediante la doble negación. ¿No forman todos ellos parte del proceso de toma de decisiones por ser cada uno, según su vocación, carismas y ministerio, miembro del cuerpo eclesial de Cristo edificado en templo espiritual y ciudadano del pueblo de Dios que camina en la historia, como sacramento de salvación? Es así que, contando con todos los fieles y tomándolos en serio, se saldrá del punto muerto del "solo consultivo". Lo cual honra su dignidad en la pirámide invertida. ${ }^{26}$ Semper in ecclesia, numquam alii sine aliis.

\section{Bibliografía}

Borras, Alphonse. «Délibérer en Église: communion ecclésiale et fidélité évangélique», Nouvelle Revue Théologique 132 (2010): 177-196.

Borras, Alphonse. «Episcopalis communio, mérites et limites d'une réforme institutionnelle», Nouvelle Revue Théologique 141 (2019/1): 66-88.

Borras, Alphonse. «La Conférence ecclésiale pour l’Amazonie, une institution synodale inédite», Ephemerides Theologicae Lovanienses 97/2 (2021): 223-292.

Borras, Alphonse. «La coresponsabilité : enjeux théologiques et institutionnels», en Olivier Bobineau \& Jean Guyon, La coresponsabilité dans l'Église, utopie ou réalisme. Paris: Desclée de Brouwer, col. Religion \& Politique, 2010, 69-89.

Borras, Alphonse. «Votum tantum consultivum. Les limites ecclésiologiques d'une formule canonique», Didaskalia 45 (2015/1): 145-162.

26 Recordémonos que, en su discurso del 17 de octubre de 2015 (véase mi nota 1), el papa Francisco utiliza esa metáfora tras haber citado a Juan Crisóstomo, «lglesia y Sínodo son sinónimos» (véase la nota anterior). 
Coccopalmerio, Francesco. «La "consultività" del Consiglio pastorale parrocchiale e del Consiglio per gli affari economici della parrocchia», Quaderni di Diritto ecclesiale 1 (1988): 60-65.

Coccopalmerio, Francesco. De paroecia. Roma: Ed. Pontificia università gregoriana, 1991.

Join-Lambert, Arnaud. Les liturgies des synodes diocésains français 1983-1999. Paris: Éd. du Cerf, col. Liturgie nº15, 2004.

Pié i Ninot, Salvador. Eclesiología. La sacramentalidad de la comunidad cristiana. Salamanca: Ed. Sígueme, col. Lux Mundi $n^{\circ}$ 86, 2007.

Pié i Ninot, Salvador. La sinodalitat eclesial. Ekklèsía suvódou estìn honoma (St Joan Crisòstom). Lliçó inaugural del curs acadèmic 19931994. Barcelona: Ed. Facultat de Teologia de Catalunya, 1993.

Rondet, Michel. «Le discernement dans la vie de l’Église», Christus 179 (1998): 275-283.

Sartorio, Ugo. «Sinodalità per una Chiesa in riforma», Studia Patavina 66 (2019): 279-292. 